\title{
Exploring saiga horn consumption in Singapore
}

\author{
Meryl Theng, Jenny A. Glikman and E. J. Milner-Gulland
}

\begin{abstract}
The Critically Endangered saiga antelope Saiga tatarica faces an uncertain future, with populations dwindling from epidemics in its range countries, and ongoing demand for its horns in the traditional Chinese medicine trade. Singapore is a major hub for the global trade in saiga horn and an important consumer country, with saiga horn products widely available in the domestic market. Despite this, little is known about the consumers that drive domestic demand. Before interventions are carried out, it is important to understand who the consumers are, and their motivations. We conducted an investigation into consumption prevalence and consumer demographics, knowledge and motivations. We surveyed 230 Chinese Singaporeans, through a combination of face-to-face interviews and selfadministered questionnaires. Recent consumption incidence (in the previous 12 months) was relatively high, at $13 \%$. Younger respondents (18-35 years) had the highest prevalence of recent consumption (25\%), often as a result of influence from an older family member or friend. Bottled saiga horn cooling water was the most popular product among recent users (50\%), followed by horn shavings $(31 \%)$ and tablets (13\%). Awareness of conservation issues and regulations was uniformly low. Awareness raising may have an effect in reducing consumer demand in Singapore. However, given the exploratory nature of this study, it is best used to guide and inform future research underlying behavioural change interventions in a relatively understudied but important consumer group, Chinese Singaporeans.
\end{abstract}

Keywords Horn, Saiga tatarica, Singapore, TCM, traditional Chinese medicine, wildlife trade

Supplementary material for this article is available at https://doi.org/10.1017/Soo30605317001624

\section{Introduction}

7 he demand for animal products for medicinal purposes is one of the major drivers of the illegal wildlife trade globally, across a range of taxa (Warchol, 2004; Nijman, 2010). This demand has led to the unsustainable killing of

Meryl Theng (Corresponding author) TRAFFIC Southeast Asia, Petaling Jaya, Selangor, Malaysia. E-mail meryltheng@gmail.com

Jenny A. Glikman Institute for Conservation Research, San Diego Zoo Global, California, USA

E. J. Milner-Gulland Department of Zoology, University of Oxford, Oxford, UK

Received 30 May 2017. Revision requested 19 September 2017.

Accepted 18 October 2017. First published online 13 March 2018. wildlife, causing rapid declines in the affected populations (Mittermeier et al., 1999; Zhang et al., 2008; Bennett, 2015; Ferreira et al., 2015). Understanding consumer behaviour and motivations is a vital component in tackling this threat, as it provides a foundation for the development of effective long-term campaigns that reduce wildlife consumption (Wasser \& Jiao, 2010; Burgess, 2016).

Singapore has a history of wildlife consumption for medicinal use (Martin, 1983; Barnard, 2014). Although there have been investigations into wildlife products for sale in the traditional Chinese medicine market (Govind \& Ho, 2001; Ng \& Burgess, 2004; Meibom et al., 2010), little work has been done to understand the local consumers that drive the trade.

Traditional Chinese medicine is regarded as being a part of Singapore's heritage and Chinese culture (Ministry of Health, 1995), and as a form of complementary and alternative medicine alongside Singapore's Western-based healthcare system. Chinese medicine shops located within housing estates, and modern franchises in shopping malls, provide traditional medicinal products over the counter throughout the country. The number of traditional Chinese medicinal products from threatened animals available in Singapore appears to have decreased since the 1980 os as a result of reduced domestic demand, trade bans on species listed on Appendix I of CITES (2017), higher penalties and increased enforcement (e.g. in relation to rhinoceros and bear products; Martin, 1983; Foley et al., 2011; AVA \& Singapore Customs, 2017; Theng \& Krishnasamy, in press). One of the few products that remains widely available is saiga horn (Theng \& Krishnasamy, in press), known locally as ling yang jiao, which is believed to be effective in reducing fevers, detoxification, assuaging epilepsy, and benefiting the liver (Zang, 1990).

The horn used in ling yang jiao comes from the saiga antelope Saiga tatarica, a nomadic herding species of the steppes and semi-desert regions of south-eastern Europe and Central Asia, of which there are two subspecies. Saiga tatarica tatarica occurs in Kalmykia, Russian Federation (one population), and in Kazakhstan (three populations: Ural, Ustiurt, Betpak-Dala), and S. tatarica mongolica occurs in Mongolia. Once abundant (Sokolov \& Zhirnov, 1998), populations have declined drastically, from $>1,000,000$ in the 1980 os to an estimated low of 178,000 in 2000 , largely as a result of uncontrolled hunting for meat and horns (Milner-Gulland et al., 2001; CMS, 2015). Horns are a key target for poachers, as they are highly prized in traditional Chinese medicine (Chan, 1995). Consequently, males have been hunted intensively, resulting in heavily skewed sex ratios and reproductive collapse (Milner-Gulland et al., 2003). 
Following conservation action the species started to recover, but a catastrophic mass die-off from bacterial infection of $>200,000$ individuals ( $>60 \%$ of the global population) in Kazakstan in May 2015 and an ongoing epidemic in Mongolia (which may kill up to $80 \%$ of the Saiga t. mongolica population) have undermined this recovery, putting the Betpak-Dala and Mongolian populations in a critical situation (Bonn, 2016; SCA, 2017). Together, the disease outbreaks and the ongoing poaching, especially of males for their horns, have resulted in saiga antelopes facing an uncertain future (SCA, 2016).

To protect the species, it was listed on Appendix II of CITES in 1995. It was categorized as Critically Endangered on the IUCN Red List in 2002 (Mallon, 2008). All saiga range countries have implemented moratoria on hunting and trade of the species at various times during 19992014, which effectively means that no export of saiga horn is permitted from range countries until the species' conservation status improves (CMS, 2017). Legal international trade in saiga horn remained high during 1995-2004, at $87,449 \mathrm{~kg}$, the largest importers being China $(34,851 \mathrm{~kg})$, Singapore $(17,186 \mathrm{~kg})$ and Japan $(13,312 \mathrm{~kg}$; Meibom et al., 2010). Singapore played an important role as the main hub of the saiga horn trade in South-east Asia, importing mainly from the Russian Federation and Hong Kong and re-exporting mainly to China, Malaysia and Hong Kong (Meibom et al., 2010). A 2016 study focused on Singapore's international and domestic saiga horn trade found that although legal import of horns had declined by 99\% over the previous decade, Singapore's stockpile of horns continues to fuel high-quantity exports to Hong Kong, China and Malaysia, and to supply the domestic trade in saiga products (Theng \& Krishnasamy, in press). Because of the domestic stockpile, consumption of saiga products is legal in Singapore, and products are displayed and bought openly. Of the 188 Chinese medical halls surveyed, $97 \%$ sold some form of saiga horn (whole horns, shavings, cooling water, tablets, tea; Theng \& Krishnasamy, in press), which was often displayed prominently and spoken about openly by vendors. The ongoing availability of the product in shops suggests there continues to be a demand, prompting the need to gain an understanding of saiga horn consumption among the Singapore populace.

We attempted to gain an understanding of consumer insights and awareness levels by surveying Chinese Singaporeans to (1) gauge the prevalence of consumption of saiga horn products, (2) identify the demographics of users, non-users and lapsed users of saiga horn products, (3) identify consumption and purchase behaviours relating to saiga horn products, (4) identify the motivations and barriers to consuming the products, and (5) gauge their level of understanding of the conservation status and harvest of the saiga antelope.

\section{Methods}

\section{Pre-survey}

A questionnaire was formulated in English and Mandarin (Supplementary Material 1). Although vendors of traditional Chinese medicine mentioned non-local purchasers of saiga horn in an earlier market survey (specifically tourists from mainland China; Theng \& Krishnasamy, in press), only local Chinese Singaporeans were surveyed. Non-Chinese people were excluded from the study to focus on the core demographic of users of traditional Chinese medicine.

The questionnaire consisted of three parts. The first comprised questions about the respondent's sociodemographic attributes, including consumption and purchase of traditional Chinese medicine. The respondents were then categorized as either users (consumed saiga horn product in the previous 12 months) or non- or lapsed users (did not consume saiga horn product in the previous 12 months). Users completed Section A, comprising questions about their consumption behaviour in relation to saiga horn products, trends between past and present use, and motivations for consumption. Non- and lapsed users completed Section B, containing questions about past use ( $>12$ months previously) and motivations for nonconsumption or recent non-consumption of saiga horn products. Both sections included questions about the use of alternatives to saiga horn (synthetic, animal- or plant-based products) and the reasons for their use instead of saiga horn products. The questionnaire was revised following a pilot survey of 19 respondents in the Choa Chu Kang neighbourhood conducted a month prior to this study.

Based on several vendors in an earlier market survey identifying elderly Chinese Singaporeans as their main local clientele for saiga horn products (Theng \& Krishnasamy, in press), we biased our sampling towards elderly people ( $>60$ years; $50 \%$ of our sample), with the middle-aged (36-59 years) and young (18-35 years) each comprising $25 \%$ of respondents.

\section{Survey administration}

The questionnaires were completed by 230 Singaporean respondents, and were either self-administered or administered through face-to-face interviews by MT and an assistant (both Chinese Singaporeans). In October and November 2016, survey sessions were conducted during 08.30-15.00 in nine public housing-dominated neighbourhoods (Bishan, Bukit Merah, Chinatown, Jurong East, Jurong West, Serangoon, Tampines, Woodlands, Yishun; Supplementary Fig. 1). The locations and times were selected based on the likelihood of people from a variety of socio-economic backgrounds being available. Given 
constraints of time and cost, potential respondents were targeted based on their likely willingness to complete a questionnaire (e.g. someone waiting for a friend rather than rushing to work). Respondents were instructed to complete the questionnaire in their preferred language (English or Mandarin), with interviewers present to clarify questions when required. Some respondents requested that questions be read aloud in an interview format. To minimize selfselection bias, potential respondents were asked if they were willing to participate in a general survey about traditional Chinese medicine, without describing the topic or intent. To protect respondents' anonymity and minimize survey sensitivity, no personal data that could be used to identify individuals were collected. We used the face-to-face approach because it garners better response rates than online, mail or telephone surveys and is usually more representative of the population compared to online surveys (Groves et al., 2009; Szolnoki \& Hoffmann, 2013).

\section{Data analyses}

Responses were accepted for analysis if the first section on demographics was completed. Statistical analysis of the survey data was performed using $R$ v. 2.7.o (R Development Core Team, 2016). Chi-square tests were used to determine whether there was a significant difference between expected and observed frequencies of consumption behaviour between the groups.

\section{Results}

We obtained responses from 230 Chinese Singaporeans (109 elderly, 66 middle-aged and 55 young; 118 female, 112 male). Overall, $13 \%$ had consumed saiga horn products recently (in the previous 12 months), with an additional $40 \%$ having consumed the product more than 12 months previously (lapsed users). Our data indicate a relationship between age class and saiga horn use $\left(\chi^{2}=7.814, \mathrm{n}=230, \mathrm{df}=2, \mathrm{P}=0.020\right)$, reflecting a higher prevalence of recent consumption among younger people (18-35 years; $25 \%$ prevalence) compared to middle-aged (36-59 years; $17 \%$ prevalence) and elderly people ( $>60$ years; $9 \%$ prevalence).

General traditional Chinese medicine consumption and purchase behaviours differed between the users and lapsed/ non-users. Recent users of saiga horn product were more likely to have also consumed and purchased other traditional Chinese medicinal products recently compared to lapsed/ non-users of saiga horn product (consumption: 97 vs $71 \%$, $\chi^{2}=9.304, \mathrm{n}=230, \mathrm{P}=0.001$; purchase: 88.6 vs $65.1 \%$, $\chi^{2}=6.533, \mathrm{n}=230, \mathrm{P}=0.005$ ). There were no significant differences in gender, education level or income level between users and lapsed/non-users.
Users

The most commonly used saiga horn product was bottled 'fresh' saiga water (49\%), followed by shavings (40\%), bottled 'supermarket' saiga water $(20 \%)$ and tablets $(17 \%$; Plate 1). Only one user had used a whole horn, which has to be shaved down and boiled before being consumed. In shops, horn shavings are usually sold in small amounts by weight or ready-packaged with herbs. Fresh saiga water is made out of horn shavings that have been boiled with water and packaged into bottles for sale in traditional Chinese medicine shops, for immediate consumption. This is different from supermarket saiga water, which is a widely available brand of cooling water that does not contain animal products and that consumers often mistake for containing ling yang jiao. Tablets usually contain saiga horn in trace amounts of $<1 \%$ and are sold as remedies for cold and fever.

For most users, overall consumption had not changed in the previous 2-3 years (69\%). Saiga horn products were obtained from a variety of sources: franchise/chain stores (34\%), privately owned stores (34\%), family/friends (23\%) and others (9\%). Regarding the users' motivations for their most recent consumption of saiga horn, more young people than middle-aged or older indicated that an elder or family member had bought it for them, and that it had been recommended by a family member or friend (Fig. 1), whereas higher numbers of middle-aged and old people had made the decision themselves to consume saiga horn. However, the differences were not statistically significant.

Fluctuations in price (by $\pm 20 \%$ ) and not knowing anyone else who used saiga horn products did not appear to be considerations in consumption decisions among most users (Fig. 2). Most respondents said they would stop consuming saiga horn if these products were banned or if they learnt that the harvest threatened the survival of saiga in the wild or was cruel.

\section{Lapsed/non-users}

Among the 195 respondents who had not consumed saiga horn in the previous 12 months, $47 \%$ had consumed it previously (i.e. lapsed users) and $51 \%$ had never consumed it (i.e. non-users). Slightly more than half of the lapsed users had not consumed saiga horn in more than 10 years $(53 \%)$, $27 \%$ had consumed it within the previous $2-3$ years, and $20 \%$ had consumed it in the previous $4-10$ years. No significant differences were found between the reasons given by lapsed and non-users for stopping/not consuming saiga horn, except that more non-users selected 'elder/family stopped buying for me' (Fig. 3). The most popular reason given by lapsed and non-users for stopping/not consuming saiga horn was not having a use or need for it ( 45 and $48 \%$, respectively). Among the 21 respondents who stated that 


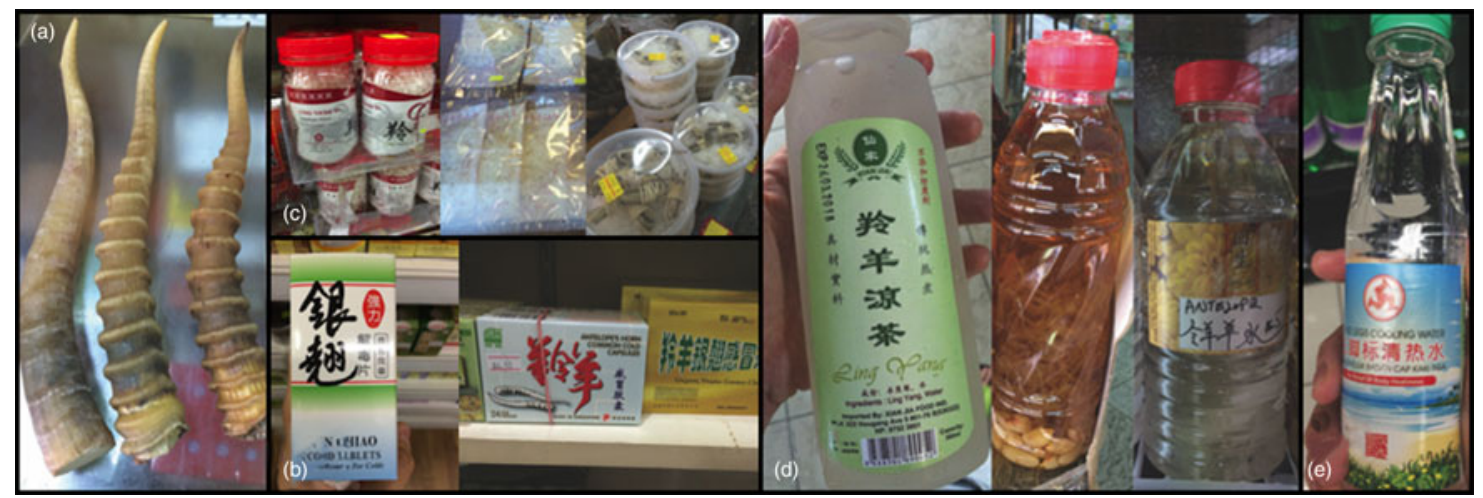

PLATE 1 Saiga horn products available in Singapore: (a) whole horns, (b) shavings, (c) tablets, (d) cooling waters, and (e) a brand of cooling water available from supermarkets, which does not contain saiga horn.

people had stopped buying horn for them, there were significantly fewer old people than young and middle aged $\left(\chi^{2}=12.79, \mathrm{P}=0.002\right)$.

\section{Reasons for using saiga horn or alternatives}

The main reason for consuming saiga horn was significantly different among users, lapsed users and non-users $\left(\chi^{2}=65.67, \mathrm{n}=225, \mathrm{P}=3.563 \mathrm{e}^{-11}\right.$; Fig. 4). Among users and lapsed users saiga horn is still widely believed to be effective as a coolant and for releasing toxins to cure related ailments such as fevers and sore throats (users: $77 \%$; lapsed users: 86\%). Among those who had not consumed saiga horn, $37 \%$ thought reducing 'heatiness' was the main reason others consumed it, but most indicated that they did not know or did not want to answer (46\%).

There was no significant difference between the groups in their use of alternatives $\left(\chi^{2}=16.71, \mathrm{n}=220, \mathrm{P}=0.081\right.$; Fig. 5). Synthetic alternatives such as paracetamol appeared to be the most popular alternative to saiga horn used in the previous 12 months (users: 40\% users; lapsed/non-users: $45 \%$ ), followed by plant-based alternatives such as herbal tea (users: $42 \%$; lapsed/non-users: $31 \%$ ), and none of the stated alternatives (users: $26 \%$; lapsed/non-users: $24 \%$ ). None of the saiga horn users indicated use of an animal-based alternative (e.g. horns from other species) and only three lapsed/non-users indicated their recent use of such an alternative. Among the reasons given for the use of alternatives instead of saiga horn, the most cited among the users was that alternatives were more readily available than saiga horn (29\%). In the lapsed and non-user group the main reason was that they had not considered using saiga horn (40\%).

\section{Awareness}

Awareness of the regulations regarding saiga horn use, the species' status and harvest methods was consistently low across all user groups and ages. Only $13 \%(n=29)$ of all respondents were aware that there were regulations on saiga horn trade (users: $0.4 \%$; lapsed: $8 \%$; non-users: $4 \%$; uncategorised: $0.6 \%)$. Of these, only two answered correctly that only licensed products can be sold; 11 did not know, and 16 answered incorrectly. Similarly, few were aware of the status of the saiga in the wild, with $79 \%$ of all respondents saying they did not know, and only $4 \%$ giving the correct answer (that the saiga occurs in several countries and some populations are declining). A higher proportion of respondents were aware that saiga are killed in the wild for their horns and meat, but awareness that this is the case was still low (13\%). The majority did not know or did not want to comment about the harvest method (72\%). When asked if they thought saiga horns could grow back after being cut off, a third of lapsed and non-users correctly answered 'no' (34\%), and $49 \%$ of users answered incorrectly.

\section{Discussion}

The main aim of this study was to explore the prevalence of saiga horn consumption among the Singaporean Chinese population and their motivations for doing so. On a broader level, we wanted to understand general consumption and purchase behaviours, and the level of knowledge about the status and conservation of the saiga. This is the first study of the consumers of a wildlife product in Singapore and provides baseline information upon which further behavioural intervention studies can be founded. As the study was conducted only in neighbourhoods dominated by public housing, our responses may be limited to low- to middle-class citizens. Furthermore, given the small sample size and the possibility of confusion of saiga with other horn products (particularly when purchased as shavings), any trends should not be taken to be a conclusive representation of the volume of trade in saiga horn.

As expected from the availability of saiga products in the Singapore market (Theng \& Krishnasamy, in press), there appears to be relatively high ongoing use of saiga horn 


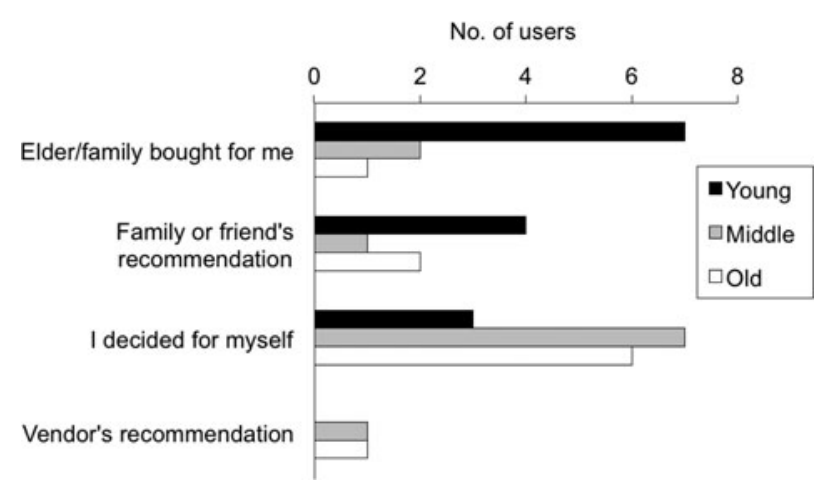

FIG. 1 Reasons for the most recent consumption of saiga horn among Chinese Singaporean users of saiga horn products $(\mathrm{n}=35)$, by age group.

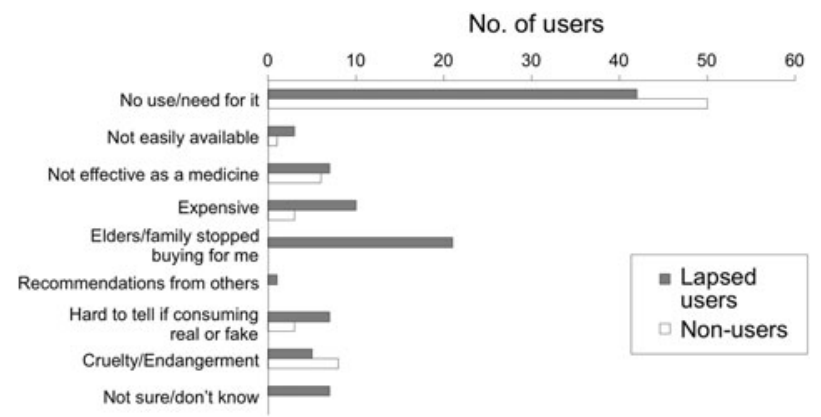

FIG. 3 Reasons for stopping or not consuming saiga horn products, according to lapsed users $(\mathrm{n}=94)$ and non-users $(\mathrm{n}=105)$ among a sample of Chinese Singaporeans. Respondents were allowed to select up to three reasons.

products in Singapore, and the trade does not appear to be in decline. Contrary to our assumption that the main local consumers of saiga horn are elderly, based on previous remarks by Chinese medicine vendors (Theng \& Krishnasamy, in press), that age group had the lowest prevalence of recent consumption, followed by the middle-aged (36-59 years) and the young (18-35 years). The significant difference in use could be attributed to the general belief that saiga horn is more effective in treating the young and that the cooling effects of the product may be detrimental to the health of the elderly, a point made by several elderly respondents during the survey. The elderly may often purchase products for the consumption of their younger kin, as a higher number of young respondents compared to both the older age groups indicated as reasons for their most recent consumption that an elder or family member had purchased saiga products for them or that a family member or friend had recommended it. This suggests there may be some intergenerational influence on the consumption of saiga horn, which could be leveraged in future behavioural change campaigns. A similar study of the consumption of animal products in traditional Chinese medicine in Beijing found the reverse, that older people were more likely than younger people to consume animal-based medicinal

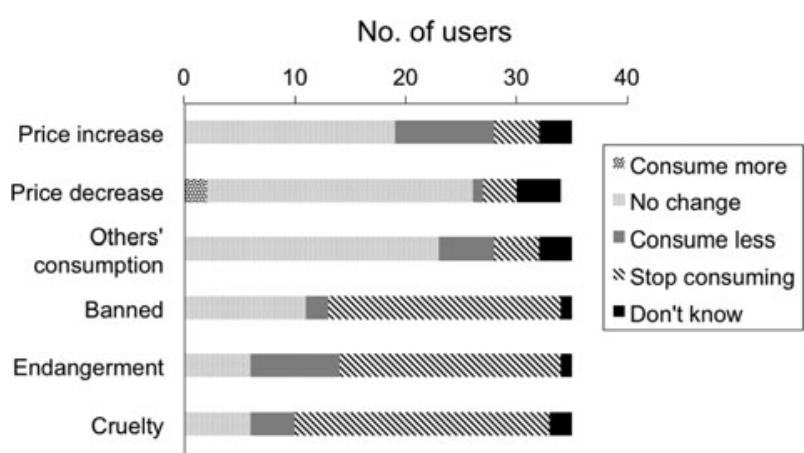

FIG. 2 The factors that Chinese Singaporean users of saiga horn products $(n=35)$ reported would or would not lead to a change in their personal consumption of those products.

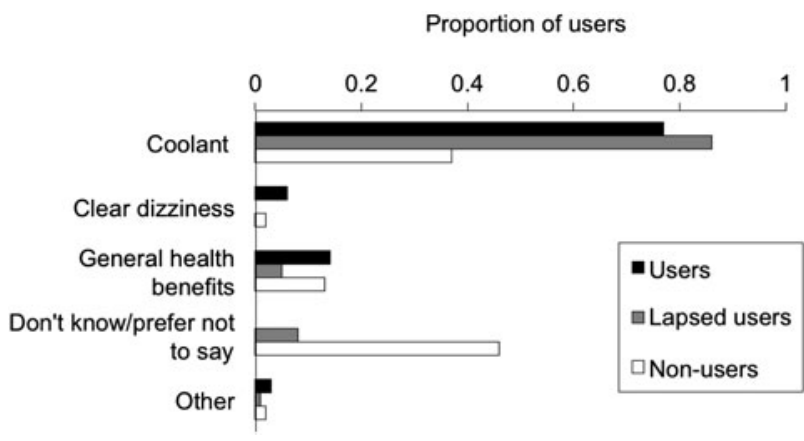

FIG. 4 The main reasons for consumption of saiga horn products, according to users $(n=35)$, lapsed users $(n=94)$ and non-users $(n=105)$ among a sample of Chinese Singaporeans.

products; however, this did not differentiate between products depending on their specific target demographic (Liu et al., 2016). Several studies on the level of use of traditional Chinese medicine in Taiwan, and one in Australia, found a similar trend, that use of traditional Chinese medicine peaked in younger adults (c. 30 years old) and was lowest among older adults (51-62 years old), although it is not known why (Sherwood, 2000; Chen et al., 2007; Daly et al., 2009; Shih et al., 2012). The same studies in Taiwan found that females were more likely than males to use traditional Chinese medicine, a finding not reflected in our study. We found that recent users of saiga horn were more likely than lapsed/non-users to have consumed and purchased other traditional Chinese medicinal products recently.

Our study suggests that consumption behaviour is not particularly price sensitive. Previous studies have demonstrated a similar phenomenon, that consumers of traditional Chinese medicine are willing to pay high prices for wildsourced animal products because they believe that these products are more potent (Gratwicke et al., 2008; Dutton et al., 2011). Saiga horn products are relatively expensive compared to the products they are grouped with in shops; for example, of the range of cooling waters routinely on 


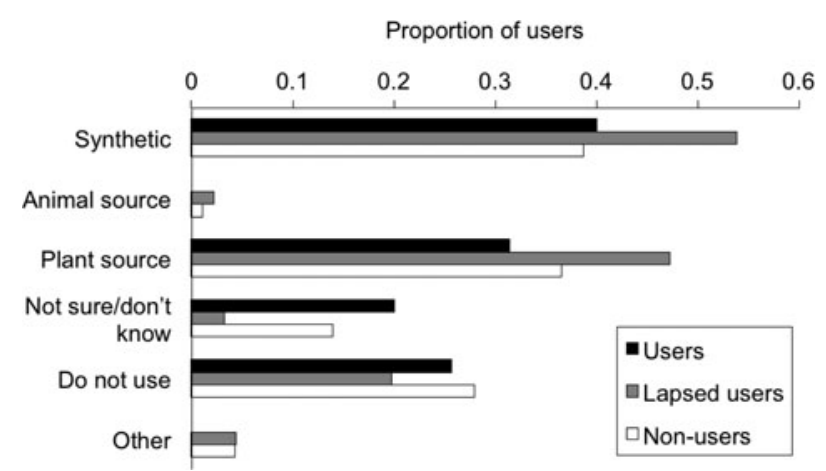

FIG. 5 Proportion of users $(n=35)$, lapsed users $(n=91)$ and non-users $(n=93)$ of saiga horn products, among a sample of Chinese Singaporeans, that consume various alternatives to saiga horn.

sale, the majority cost c. SGD 2, compared to SGD 5 for saiga water (authors, pers. obs.). This may be because saiga water is generally considered to be particularly strong and effective as a cooling product (authors, pers. obs.).

Awareness about regulations, status and harvest methods relating to the saiga was low. Most respondents knew ling yang jiao as a traditional Chinese medicinal product and understood its effects, but did not know much more than that. Although this product is widely available and well known among the local Chinese community in Singapore, there is a need to explain the harvesting methods used and the status of the species, which may have an impact on consumer behaviour. According to respondents they would be most likely to stop consuming saiga horn if the product was banned, if the practice caused the saiga to be threatened or if harvest practices were cruel (Fig. 2), indicating potential for raising conservation awareness to reduce demand. It has previously been argued that conservation awareness has an important impact on consumer behaviour in the wildlife trade context (Nowell \& Xu, 2007; Wasser \& Jiao, 2010). It has been effective in decreasing the demand for shark fin in Singapore (WWF Singapore, 2016) and could also be leveraged to reduce the trade in saiga horn. A study in Beijing found that as conservation awareness among survey respondents increased, they were more likely to choose substitutes and less likely to choose wild-sourced animal-based traditional medicinal products (Liu et al., 2016). It appears that many of our respondents already use alternatives to saiga horn, generally to cool the body and cure related ailments such as fever. The use of horns from other species (i.e. water buffalo Bubalus bubalis, sheep Ovis aries and goat Capra hircus) as substitutes does not appear to be popular, possibly because they are perceived as being too weak to cure ailments such as persistent fevers (according to vendors) or are usually sold in the form of shavings rather than the more popular cooling waters (Theng \& Krishnasamy, in press). The synthetic alternative (Western medicine, e.g. paracetamol) is popular mostly because it is more widely available; however, a quarter of saiga horn users said they did not use a substitute.

Given the exploratory nature of this study, our observations and suggestions are neither representative nor conclusive. Future studies could explore promoting the use of effective synthetic alternatives, which are cheaper and more readily available than saiga horn, to treat fever, and consumption of herbal tea to cool the body. There is a need for a deeper understanding of the thought process involved in deciding between the use of saiga horn or an alternative to treat an ailment, as conservation awareness alone may not drive behavioural change and subsequent demand reduction (Lertzman \& Baragona, 2016). It is important to investigate the attitudes saiga horn users generally have towards traditional Chinese medicine versus Western medicine; for example, in Hong Kong some consumers of traditional medicine perceive that Western medicine is sometimes too powerful, with significant side effects, and prefer traditional medicine because it is believed to cure the root of the problem (Lam, 2001).

\section{Future research perspectives}

This study was the first in Singapore to examine consumer relationships with a traditional Chinese medicinal product derived from a Critically Endangered species. Although suggestive findings emerged, the study was exploratory in nature. Sampling was opportunistic and focused on older consumers, and the sample size was small. Despite the relatively high prevalence of saiga horn use, the number of recent users was small, and therefore any trends derived should not be considered to be a conclusive representation of the population. Future surveys could be randomized to improve representativeness. It will also be important to examine whether saiga horn consumption is a sensitive issue, potentially necessitating an indirect questioning method (Nuno \& St. John, 2015), and to investigate its price sensitivity.

This research is being used to guide and inform more detailed research underlying behavioural change interventions. This includes understanding the motivations and demographics of users of traditional Chinese medicine, to design and implement effective behavioural change campaigns. Too often, campaigns are implemented without a robust foundation in behavioural science (Olmedo et al., 2017). This survey lays the foundation for a more detailed understanding of the identity and attitudes of the consumers of a particularly important medicinal product, saiga horn, in a relatively understudied but important consumer group, Chinese Singaporeans. We have shown that saiga horn use is relatively prevalent, awareness of the conservation issues and relevant legislation is low, and younger people in particular are using saiga products, especially cooling 
water. These results suggest that an awareness-raising campaign that focuses on this demographic group and product type may be a useful approach to reducing consumption of saiga horn; such a campaign is now under development by E. J. Milner-Gulland and Hunter Doughty. It is also vital to investigate the prevalence and characteristics of the trade in saiga products in other countries and online, to tackle the dearth of information about the trade in this Critically Endangered species.

\section{Acknowledgements}

We are grateful to Roopali Raghavan of Wildlife Reserves Singapore for initiating and facilitating the collaboration between TRAFFIC South-east Asia and Oxford University, and Madelon Williams of TRAFFIC Vietnam for initiating the collaboration with San Diego Zoo Global. EJMG acknowledges the support of the Oxford Martin Programme on the Illegal Wildlife Trade. We thank Joys Tan and Joleen Chan for their assistance, and Dr Martin Fisher and two anonymous reviewers for providing invaluable comments. This study was funded by WWF Singapore.

\section{Author contributions}

MT, JAG and EJMG designed the questionnaire and survey methods, and MT conducted the survey. MT led the writing, with the support of EJMG.

\section{References}

AVA \& Singapore Customs (2017) Joint news release: illegal rhino horns seized. 1 September 2017. Agri-food \& Veterinary Authority and Singapore Customs, Singapore.

B ARnard, T.P. (2014) Nature Contained: Environmental Histories of Singapore. NUS Press, Singapore.

BennetT, E.L. (2015) Legal ivory trade in a corrupt world and its impact on African elephant populations. Conservation Biology, 29, $54-60$

Bonn (2016) Signs of Hope for Saiga Antelope after Mass Die-off in 2015. Memorandum of Understanding Concerning Conservation, Restoration and Sustainable Use of the Saiga Antelope. Http://www. $\mathrm{cms}$.int/saiga/en/news/signs-hope-saiga-antelope-after-massdie-2015 [accessed 13 September 2016].

Burgess, G. (2016) Powers of persuasion? Conservation communications, behavioural change and reducing demand for illegal wildlife products. TRAFFIC Bulletin, 28, 65-73.

CHAN, S. (1995) A survey of markets for saiga horns in East and Southeast Asia. In From Steppe To Store: The Trade In Saiga Antelope Horn (eds S. Chan, A.V. Maksimuk, L.V. Zhirnov \& S. V. Nash), pp. 32-41. TRAFFIC International, Cambridge, UK.

Chen, F.P., Chen, T.J., Kung, Y.Y., Chen, Y.C., Chou, L.F., Chen, F. J. \& HWANG, S.J. (2007) Use frequency of traditional Chinese medicine in Taiwan. BMC Health Services Research, 7, 26.

CITES (2017) Convention on International Trade in Endangered Species of Wild Fauna and Flora. Appendices I, II and III. Http:// cites.org/eng/app/appendices.php [accessed 26 October 2017].
CMS (Convention on Migratory Species) (2015) Third Meeting of the Signatories to the Memorandum of Understanding Concerning Conservation, Restoration and Sustainable Use of the Saiga Antelope Tashkent, Uzbekistan, 26-29 October 2015. UNEP/CMS Secretariat, Bonn, Germany.

CMS (Convention on Migratory Species) (2017) Saiga Antelope: National Reports. Memorandum of Understanding Concerning Conservation, Restoration and Sustainable Use of the Saiga Antelope. Http://www.cms.int/saiga/en/documents/ national-reports/ [accessed 1 October 2017].

Daly, M., TAi, C.J., Deng, C.Y. \& Chien, L.Y. (2009) Factors associated with utilization of traditional Chinese medicine by white collar foreign workers living in Taiwan. BMC Health Services Research, 9, 10.

Dutton, A.J., Hepburn, C. \& Macdonald, D.W. (2011) A stated preference investigation into the Chinese demand for farmed vs. wild bear bile. PLOS ONE, 6(7), e21243.

Ferreira, S., Greaver, C., Knight, G., Knight, M., Smit, I. \& PienaAR, D. (2015) Disruption of rhino demography by poachers may lead to population declines in Kruger National Park, South Africa. PLoS ONE, 10(6), e0127783.

Foley, K.E., Stengel, C.J. \& Shepherd, C.R. (2011) Pills, Powders, Vials and Flakes: The Bear Bile Trade in Asia. TRAFFIC Southeast Asia, Petaling Jaya, Selangor, Malaysia.

Govind, V. \& Ho, S. (2001) The Trade in Bear Gall Bladder and Bear Bile Products in Singapore. Animal Concerns Research and Education Society, Singapore.

Gratwicke, B., Bennett, E.L., Broad, S., Christie, S., Dutton, A., Gabriel, G. et al. (2008) The world can't have wild tigers and eat them, too. Conservation Biology, 22, 222-223.

Groves, R.M., Fowler, Jr, F.J., Couper, M.P., Lepkowski, J.M., Singer, E. \& Tourangeau, R. (2009) Survey Methodology. 2nd edition. John Wiley \& Sons, Hoboken, USA.

LAM, T.P. (2001) Strengths and weaknesses of traditional Chinese medicine and Western medicine in the eyes of some Hong Kong Chinese. Journal of Epidemiology \& Community Health, 55, 762-765.

Lertzman, R. \& Baragona, K. (2016) Reducing Desire for Ivory: A Psychosocial Guide to Address Ivory Consumption. Http://www. changewildlifeconsumers.org/wp-content/uploads/2016/o2/ ReducingDesireforIvory_011917_print-1.pdf [accessed 26 March 2017].

LiU, Z., Jiang, Z., FanG, H., Li, C., Mi, A., Chen, J. et al. (2016) Perception, price and preference: consumption and protection of wild animals used in traditional medicine. PLoS ONE, 11(3), e0145901.

MALLON, D. (2008) Saiga tatarica. In The IUCN Red List of Threatened Species 2008: e.T19832A9021682. Http://dx.doi.org/10.2305/IUCN. UK.2008.RLTS.T19832A9021682.en [accessed 26 October 2017].

MARTin, E.B. (1983) The decline in the trade of rhinoceros horn. Swara, 6, 10-15.

Meibom, S.V., Vaisman, A., Neo Liang, S.H., NG, J. \& Xu, H. (2010) Saiga Antelope Trade: Global Trends with a Focus on South-East Asia. TRAFFIC project report to the CITES Secretariat. TRAFFIC Europe, Brussels, Belgium.

Milner-Gulland, E.J., Bukreeva, O.M., Coulson, T., Lushchekina, A.A., Kholodova, M.V., Bekenov, A.B. \& Grachev, I.A. (2003) Conservation: Reproductive collapse in saiga antelope harems. Nature, 422, 135.

Milner-Gulland, E.J., Kholodova, M.V., Bekenov, A., Bukreeva, O.M., Grachev, I.A., Amgalan, L. \& Lushchekina, A.A. (2001) Dramatic decline in saiga antelope populations. Oryx, $35,340-345$.

Ministry of Health (1995) Practice of consultation of TCM Practitioners by the Singapore Population, 1994. Annex 4 Page 1 of a report by the Committee on TCM Oct 1995. Singapore: Ministry of Health. 
Mittermeier, R.A., Myers, N., Robles-Gil, P. \& Mittermeier, C. G. (1999) Hotspots: Earth's Biologically Richest and Most Endangered Terrestrial Ecoregions. CEMEX/Agrupación Sierra Madre, Mexico City, Mexico.

NG, D. \& Burgess, E.A. (2004) Against the Grain: Trade in Musk Deer Products in Singapore and Malaysia. TRAFFIC Southeast Asia, Petaling Jaya, Selangor, Malaysia.

Nijman, V. (2010) An overview of international wildlife trade from Southeast Asia. Biodiversity and Conservation, 19, 1101-1114.

Nowell, K. \& XU, L. (2007) Lifting China's tiger trade ban would be a catastrophe for conservation. Cat News, 46, 28-29.

Nuno, A. \& S T. John, F.A.V. (2015) How to ask sensitive questions in conservation: a review of specialized questioning techniques. Biological Conservation, 189, 5-15.

Olmedo, A., Sharif, V. \& Milner-Gulland, E.J. (2017) Evaluating the design of behavior change interventions: a case study of rhino horn in Vietnam. Conservation Letters, http://dx.doi.org/10.1111/ conl.12365.

R Development Core Team (2016) R: A Language and Environment for Statistical Computing. R Foundation for Statistical Computing, Vienna, Austria. Https://www.R-project.org/.

SCA (Saiga Conservation Alliance) (2016) Saiga News. Winter 2015/Spring 2016, Issue 20. Http://saiga-conservation.org/news/ saiga-news.

SCA (Saiga Conservation Alliance) (2017) Tragic Saiga Deaths in Mongolia. Http://www.saiga-conservation.org/2017/01/11/ tragic-saiga-deaths-in-mongolia/ [accessed 29 March 2017].

Sherwood, P. (200o) Patterns of use of complementary health services in the south-west of Western Australia. The Australian Journal of Rural Health, 8, 194-200.

Shin, C.C., LiaO, C.C., Su, Y.C., Tsai, C.C. \& Lin, J.G. (2012) Gender differences in traditional Chinese medicine use among adults in Taiwan. PLoS ONE, 7(4), e32540.

Sokolov, V.E. \& Zhirnov, L.V. (eds) (1998) The Saiga: Phylogeny, Systematics, Ecology, Conservation and Use. Russian Academy of Sciences, Moscow, Russia.
Szolnoki, G. \& Hoffmann, D. (2013) Online, face-to-face and telephone surveys-comparing different sampling methods in wine consumer research. Wine Economics and Policy, 2, 57-66.

Theng, M. \& Krishnasamy, K. (in press) An Assessment of Trade in Saiga Horn in Singapore. TRAFFIC Southeast Asia, Petaling Jaya, Selangor, Malaysia.

WARCHOL, G.L. (2004) The transnational illegal wildlife trade. Criminal Justice Studies, 17, 57-73.

Wasser, R.M. \& JiaO, P.B. (2010) Understanding the Motivations: The First Step Toward Influencing China's Unsustainable Wildlife Consumption. TRAFFIC East Asia, Beijing, China.

WWF Singapore (2016) Singapore: Shark Fin Consumer Survey. WWF Survey SG 2016, Singapore. Http://d2ouvy59podg6k. cloudfront.net/downloads/singaporesharkfinreport2016_1.pdf [accessed 10 February 2018].

ZANG, Z. (1990) A textual research on the history of lingyang. Nanjing Chinese Medical College Magazine, 6, 57-59.

ZhaNG, L., WU, S. \& BAO, Y. (2008) Current status of Chinese pangolin Manis pentadactyla in the wild: a rapid range wide population assessment. In Proceedings of the Workshop on Trade and Pangolins Native to South and Southeast Asia, 30 June-2 July 2008, Singapore Zoo (eds S. Pantel \& S.Y. Chin), p. 103. TRAFFIC Southeast Asia, Petaling Jaya, Selangor, Malaysia.

\section{Biographical sketches}

Meryl Theng's research interests are in understanding the impacts of wildlife trade and environmental change on wild animal populations. Jenny Glikman is the social scientist of the San Diego Zoo's Institute for Conservation Research. She develops and helps establish human dimensions research in community-based conservation programmes globally. E.J. MiLNER-GULLAND's research is focused on better understanding and influencing human behaviour and its impact on natural systems (for further details, see http:// www.iccs.org.uk). 